\title{
Ruipérez y su legado en Letras Clásicas
}

\author{
Silvia AQUINO LóPEZ \\ https://orcid.org/0000-0003-2132-6862 \\ Universidad Nacional Autónoma de México, México \\ slaquino@unam.mx
}

PALABRAS ClAVE: clásicos, griego, tradición clásica

KeYwords: Classics, Greek, Classical Tradition

RECIBIDO: 30/04/2020 • ACEPTADO: 15/05/2020 • VERSIÓN FINAL: 20/06/2020

\section{PREÁmbUlo}

Martín Sánchez Ruipérez, conocido internacionalmente como Ruipérez, falleció el 2 de julio de 2015 en Madrid, a los 92 años. Fue catedrático de Filología Clásica y de Lingüística Comparada Indoeuropea, primero en la Universidad de Salamanca y luego en la Complutense de Madrid. Obtuvo el honoris causa en Salamanca, España, y en Nancy, Francia. Cultivaba la lingüística histórica griega (morfología, sintaxis y semántica de griego antiguo), indoeuropea y estructural, también la filología micénica. "Puede considerarse - como a su muerte se dijo en España - uno de los helenistas más eminentes que haya dado la ciencia española y de los que mayor impacto y escuela han dejado en la filología de nuestro país". ${ }^{1}$ Vino por primera vez a la Universidad Nacional Autónoma de México (UNAM) en julio de 1981.

La escuela lingüística y filológica que Ruipérez formó en España permitió que algunos de sus destacados discípulos contribuyeran a nuestra formación académica. Varios colegas y estudiantes mexicanos conocimos a Antonio López-Eire de la Universidad de Salamanca, quien en 1985 nos dio un curso de retórica griega, además publicó y reeditó aquí su obra Esencia y objeto de la Retórica. Ha estado también Emilio Crespo, de la Universidad Autónoma de Madrid, primero desarrollando sus teorías de sintaxis griega ${ }^{2} \mathrm{y}$, luego, lo escuchamos en un curso intensivo sobre la Ilíada de Homero. Hace años tratamos a José Luis García-Ramón, ${ }^{3}$ quien en 1989 publicó, junto con Emilio

${ }^{1}$ Cf. la página de la Sociedad Española de Estudios Clásicos, www.estudiosclasicos.org, Jornada en memoria de Martín Ruipérez, 33, 2 jul 2015.

${ }^{2}$ Al lado de Luz Conti y Helena Maquieira publicó el libro Sintaxis del Griego Clásico, Maḍrid Gatedradios, 2093 ingüística Indoeuropea en la Universidad de Colonia, Alemania. 
Crespo, y donó a la Biblioteca Rubén Bonifaz Nuño los Opuscula Selecta en honor a su profesor. Julián Méndez Dosuna, del Departamento de Filología Clásica e Indoeuropea de la Universidad de Salamanca, participó brillantemente en el III Congreso Internacional de Estudios Clásicos en México, llevado a cabo en 2011. ${ }^{4}$ Finalmente, Manuel García Teijeiro, de la Universidad de Valladolid, impartió cursos sobre la magia griega e intervino en el II Coloquio Internacional Paola Vianello (2009). Ruipérez, catedrático emérito de Filología Griega de la Universidad Complutense de Madrid, participó en el libro Ágalma. Ofrenda desde la Filología Clásica, en homenaje a la jubilación "sin júbilo" - como decía Ruipérez - de García Teijeiro, publicando un conciso texto acerca del nombre de la ciudad de Salamanca. Argumentó que el primer compuesto, Sala(s) es la designación del vado de un río. Citaba también el nombre de la isla de Salamina donde en el 480 a. C. se entabló la famosa batalla naval entre las ciudades-estado griegas contra el rey persa, de quien afirma Ruipérez: "[éste] hubo de retirar sus grandes naves del estrecho entre la isla de Salamina y el continente en el cual los griegos podían pisar el suelo o utilizar pequeñas embarcaciones de muy poco calado y lograr por ella la victoria de Salamina. Es decir, se trataba de un vado". ${ }^{5}$

El vínculo que tuvimos los profesores de mi generación y los subsiguientes con España se debió a que los doctores Germán Viveros, emérito de nuestra institución, y Roberto Heredia,${ }^{6}$ cuando dirigían las áreas académicas de nuestra carrera, invitaron a magníficos académicos españoles, que en general provenían de Salamanca y de Madrid, para impartir cursos intensivos. La idea era crear una planta rigurosa de filólogos mexicanos. ${ }^{7}$

Es difícil nombrar a todos los investigadores españoles que aportaron sus conocimientos a la carrera de Letras Clásicas en la Facultad de Filosofía y Letras. Entre ellos tan sólo mencionaremos al erudito José S. Lasso de la Vega y a Sebastián Mariner Bigorra. Vinieron también Carmen Codoñer de Salamanca, hoy jubilada, y su sobresaliente alumno Gregorio Hinojo Andrés. ${ }^{8}$ Las enseñanzas de todos ellos ampliaron nuestros horizontes académicos hasta el punto de que, en 2005 (del 5 al 9 de septiembre), gracias a la idea que promovió con entusiasmo Paola Vianello, se realizó el I Congreso Internacional de

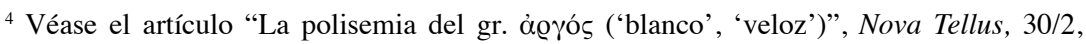
2012, pp. 11-37.

${ }^{5}$ Ángel Martínez Fernández et al. (eds.), Ágalma. Ofrenda desde la Filología Clásica a Manuel García Teijeiro, Valladolid, Ediciones Universidad de Salamanca, 2014, pp. 385-386.

${ }^{6}$ Fallecido en la Ciudad de México el 3 de noviembre de 2012.

${ }^{7}$ Paola Vianello Tessarotto compaginaba mucho con estas ideas e incluso impulsó a los jóvenes académicos para que estudiaran en Francia, Inglaterra, Italia y España. Entre los jóvenes historiadores y filólogos clásicos se encontraban Ricardo Martínez-Lacy, Gerardo Ramírez Vidal, Omar Álvarez Salas y la que suscribe.

${ }^{8}$ Fallecido el 16 de marzo de 2017. 
Estudios Clásicos en México cuando conocimos personalmente al inolvidable Luis Gil, generoso amigo de Ruipérez.

\section{RUIPÉREZ Y LA LINGÜÍSTICA}

El 21 de mayo de 1993, a la edad de 70 años, en la sección literaria del periódico $A B C$, Ruipérez publicó una reseña del último libro del lingüista francés André Martinet, "Mémoires d'un linguiste. Vivre les langues", que empieza así:

Entre las llamadas ciencias del hombre, la lingüística moderna, salida de las enseñanzas del ginebrino Ferdinand de Saussure, ocupa un lugar de honor en el siglo XX no sólo por las conquistas llevadas a cabo en el conocimiento del lenguaje humano, sino también por haber servido de estímulo y modelo para otros empeños afines, comenzando por la antropología estructural de LéviStrauss. Si el lenguaje articulado es exclusivo de la especie humana, un humanismo a la altura de nuestro tiempo no puede menos de conceder a la lingüística un lugar preeminente. Así lo hacen muchas Universidades norteamericanas, en cuyos «curricula» de antropología figuran cursos de lingüística. No se trata ya, pues, de conocimientos gramaticales al servicio del análisis literario, ni de unas recetas para uso de los escritores. Liberada de esa situación de servidumbre, la lingüística, gracias a Saussure, se convierte, en los primeros años del siglo Xx, en la ciencia semiológica por excelencia, en ciencia del significado.

La difusión de las enseñanzas de Saussure, publicadas en 1911 por dos de sus discípulos, dio lugar a la aparición de diversas «escuelas» en Europa (la de Praga de la pre-guerra, que opera con sustancia fónica y semántica; la de Copenhague, que lo hace con unidades vacías de esa sustancia) y en América. ${ }^{9}$

Ruipérez rescata la concepción dinámica de las lenguas como realidades cambiantes, considera los Élements de linguistique général de Martinet (1960) como una "auténtica joya de introducción a la lingüística". ${ }^{10}$

Ruipérez tuvo la necesidad de ubicar a su propio país de la siguiente manera:

Junto a Tovar, que no cultivó el estructuralismo, pero que sí favoreció contactos personales, aparecen citados Alarcos ${ }^{11}$ al que reprocha sus desvíos glosemáticos, Michelena - cuya reconstrucción del vascuence común a partir de los dialectos es de inspiración netamente martinetiana - y el autor de estas

\footnotetext{
${ }^{9}$ Cf. el periódico madrileño ABC CULTURAL, núm. 81, 21 de mayo de 1993, p. 23.

${ }^{10}$ ABC CULTURAL, p. 23.

${ }^{11}$ Se trata de Emilio Alarcos Llorach (1922-1998), filólogo románico.
} 
líneas, que lo es también de varios estudios de este tipo sobre griego antiguo con los que Martinet muestra reiteradamente su identificación. ${ }^{12}$

Ruipérez rechaza tajantemente, como Martinet, la lingüística de Chomsky, la llamada generativa o transformacional, a causa de su formalismo descriptivo que no avanza en el conocimiento del objeto y, en torno al griego y al latín, dice: "La impresión personal es que la moda de la lingüística chomskiana - creemos que pasajera - ha relegado a un segundo plano los análisis funcionales, que han tenido y seguirán teniendo en Martinet la fuente más rica de inspiración". ${ }^{13}$

Tovar, Michelena y Ruipérez vivieron en una etapa muy difícil para su país, pero se convirtieron en grandes lingüistas teóricos.

Parangonando a Ruipérez con Saussure (1857-1913) habría que decir que este último, en 1879, tuvo una gran intuición lingüística al afirmar la existencia de coeficientes sonánticos (o cualidades vocálicas) que no se habían conservado en otras lenguas indoeuropeas. Esta idea fue confirmada después, en 1902, por la asociación del hitita con el indoeuropeo; en el caso de Ruipérez, su reconstrucción lingüística de las desinencias medias *to y *toi del griego antiguo, año $1952,{ }^{14}$ fue anterior al descubrimiento y comprobación del micénico y de los testimonios arcadios. Ambos lingüistas son eminentes maestros del método estructural, inaugural en la teoría de la comunicación.

\section{RUIPÉREZ Y LA MICENOLOGÍA}

En sus inicios como académico en Salamanca, el especialista se dedicó a la micenología. Esta disciplina había comenzado con el descubrimiento de las tablillas micénicas en Cnosos, por Arthur Evans, en 1900, creándose una nueva etapa de estudios filológicos griegos, continuando con el desciframiento de la escritura lineal B por Michael Ventris en 1952, es decir, la lectura de la lengua griega del II milenio a. C.

$\mathrm{Al}$ respecto, existe un libro fundamental para los alumnos de Letras Clásicas en México, sobre todo para quienes estudian a Homero: Los griegos micénicos.$^{15}$ Los autores son Ruipérez y José Luis Melena, quienes dicen en su Presentación que "la historia documentada de Grecia comienza unos sete-

\footnotetext{
${ }^{12}$ ABC CULTURAL, p. 23.

${ }^{13}$ ABC CULTURAL, p. 23.

${ }^{14}$ Véase, "Desinencias medias primarias indoeuropeas sg. 1. ${ }^{\mathrm{a}} *_{-}(\mathrm{m}) \mathrm{ai}, 2{ }^{\mathrm{a}} *_{-}-\mathrm{soi}, 3$. $^{\mathrm{a}} *_{-}(\mathrm{t}) \mathrm{oi}$, pl. 3. *-ntoi”, Emerita, 20, 1952, pp. 8-31.

${ }^{15}$ Para más detalles, véase Silvia Aquino López, "Ruipérez, Martín S. y Melena, José Luis, Los griegos micénicos, Madrid, Historia 16 (Biblioteca Historia 16, 26), 1990”, Nova Tellus, 8, 1990, pp. 267-273.
} 
cientos años antes de lo que sucedía a lo largo de cerca de tres mil quinientos años de textos atestiguados casi sin solución de continuidad" ${ }^{16}$ De manera que, en el mismo lugar, es claro el estudio "de la lengua, de la geografía, de la organización política, social, administrativa y militar, de la economía, de la religión de unas gentes que fueron los antepasados de los griegos del I milenio, cuya experiencia constituye una de las parcelas más trascendentes y más importantes de la historia del hombre sobre nuestro planeta". ${ }^{17}$

Sin duda la lengua micénica corresponde a la fase pre-dialectal y es capital para estudiar la lengua griega. Ruipérez descubrió el significado de algunas tablillas. Después fue editor y luego presidente de la connotada revista Minos que hasta el año 2003 se publicaba en Salamanca. En esa Universidad organizó el Quinto Coloquio Internacional de Estudios Micénicos,$^{18}$ en 1970, al lado de los más importantes lingüistas del momento: John Chadwick y Michel Lejeune.

Ruipérez escribió muchos artículos sobre el dialecto micénico, el genitivo singular temático, las formas subjuntivas, los nombres de Perséfone, de Dionisos, de Ártemis (este último lo publicó Nilsson en el Kleine Pauly) o hasta una carta real referente a tierras en Pilos. En 1952, como arriba se ha mencionado, dedujo las desinencias medias indoeuropeas * to $\mathrm{y} *$ toi, confirmadas, un año después, por los datos del micénico. Publicó el libro Estructura del sistema de aspectos y tiempos en griego antiguo. Análisis funcional sincrónico en 1954 (1991² y la traducción francesa en 1982), así como la llamada "Ley Ruipérez" que extrajo del libro de Coseriu en el sentido de que no existe una interferencia entre las oposiciones morfológicas y las oposiciones semánticas, así como su célebre estudio sobre el vocalismo griego ${ }^{19}$ de 1956.

\section{RUIPÉREZ Y ANTONIO TOVAR EN SALAMANCA}

Ambos profesores vivieron los 36 años de la Dictadura Franquista. Dice Ruipérez en un texto de homenaje a su maestro Tovar:

Entonces tocó a los universitarios salmantinos la difícil etapa del nacional catolicismo, con Pla y Deniel y, sobre todo, con su sucesor en la diócesis salmantina, un dominico de miras cortas, fray Francisco Barbado Viejo. Tovar,

${ }^{16}$ Los griegos micénicos, Madrid, Historia 16 (Biblioteca de la Historia 16, 26), 1990, p. 9.

${ }^{17}$ Los griegos micénicos, Madrid, Historia 16 (Biblioteca de la Historia 16, 26), 1990, p. 9.

${ }^{18}$ M. S. Ruipérez (ed.), Acta Mycenaea. Actes du Cinquième Colloque International des Études Mycéniennes, tenu à Salamanca, 30 mars-3 avril 1970, donde publicó su famoso capítulo: "Le dialecte mycénienne".

${ }^{19}$ Expuesto con gran lucidez por Omar Álvarez Salas en el Homenaje Académico al Profesor Martín S. Ruipérez que se indica infra. 
creyente sincero, con ribetes de librepensador y de liberal fue, al fin y al cabo, respetado por su posición importante todavía en la política y también por su moral intachable en su vida familiar y profesional. Pero los dardos se dirigieron contra varios discípulos, como si éstos tuviesen vinculación ideológica con el maestro, cosa que éste nunca ni pidió, ni siquiera insinuó. ${ }^{20}$ Desde los púlpitos se hacía una guerra implacable a la facultad de Letras, y todavía en 1961, en tiempos del rector Balcells, el obispo logró montar una especie de auto de fe, basado en la delación anónima, contra ciertos catedráticos que en sus clases leían a Aristófanes, o a Valle-Inclán, o mandaban leer a Huxley o a Anatole France, o sencillamente explicaban que en el Japón de la posguerra estaba autorizado el aborto como medio de lucha contra el crecimiento demográfico. El fantasma de Tovar se les aparecía en esa caza de brujas. ${ }^{21}$

Es difícil hablar de todos los trabajos que realizaron conjuntamente Ruipérez y Tovar. Menciono solamente la revisión que Ruipérez hizo de la primera edición española de La Constitución de los atenienses publicada por Tovar ${ }^{22}$ y, de manera especial, la Historia de Grecia ${ }^{23}$ donde escribe la primera parte: La historia de Grecia hasta el final de la Guerra del Peloponeso. Recorre el paleolítico y neolítico, describiendo una historia de la lingüística y de la arqueología como elementos fundamentales para la comprensión del desarrollo del mundo griego. Las migraciones indoeuropeas son analizadas de manera muy cuidadosa y precisa con el fin de comprender los avances culturales en las diferentes zonas griegas dialectales. Es muy interesante la primera parte del libro porque Ruipérez usó ya los documentos de la lineal "B". El autor no olvida el elemento de base de los pueblos autóctonos y afirma que los grupos indoeuropeos no se pueden concebir absolutamente uniformes. Tampoco prescinde de los fenómenos naturales o cambios climáticos como el de la isla de Tera y la importancia de los hallazgos de la época micénica. Resulta fundamental un capítulo sobre la creación del alfabeto, donde, entre otros ejemplos, incluye la famosa Inscripción de la copa de Néstor (hacia 700 a. C.), hallada

${ }^{20}$ Las cursivas son nuestras.

${ }^{21}$ Cf. Martín S. Ruipérez, "Semblanza de un Maestro", en el periódico El País, Madrid, jueves 12 de marzo de 1981. Puede leerse en https://elpais.com/diario/1981/03/13/cultura/353286002_850215.html. La personalidad de Tovar y sus cambios políticos e ideológicos (de falangista liberal a experto lingüista en Salamanca y profesor visitante en América Latina y de la Universidad de Tubinga) son ahora ampliamente conocidos; sobre todo, debe rescatarse su separación, desde 1958, con el régimen franquista, lo cual puede verse en las Confesiones de Antonio Tovar [entrevista], por Juan Luis Cebrián en la Biblioteca Virtual Miguel de Cervantes, http://www.cervantesvirtual.com/obra visor/confesiones-de-antonio-tovar/html/

${ }^{22}$ Aristóteles, La Constitución de Atenas, ed., trad. y notas, con est. prel. Antonio Tovar, Madrid (Instituto de Estudios Políticos), 1948. Tovar cita la colaboración de Francisco Rodríguez Adrados, recientemente fallecido.

${ }^{23}$ Con numerosas ediciones y reimpresiones: 1960, 1979, 1983 de la editorial Montaner y Simon de Barcelona. 
en 1954 en la isla de Isquia, frente a Cumas, antigua colonia de Pitecusas, la cual es una muestra de la antigua difusión del alfabeto griego. No podían faltar el comercio, la religión (aspecto que a Ruipérez le había interesado mucho ${ }^{24}$ y las colonizaciones hacia Magna Grecia y hacia el norte de África. Algunos colegas centroamericanos de Letras Clásicas, en especial de Colombia, han comentado la trascendencia de este libro en la enseñanza. La claridad de este libro es la claridad que Ruipérez pedía siempre a un filólogo. Con base en todo esto es obvio que, junto con algunos alumnos, Ruipérez se dedicara, muchos años después, a Homero, tanto a la Ilíada como a la Odisea, publicando sendos libros basados en su conocimiento de la lengua homérica. ${ }^{25}$

\section{RUIPÉREZ EN LA FUNDACIÓN PASTOR}

Desde 1989 hasta 2004 dirigió la Fundación Pastor de Estudios Clásicos, entidad privada y no lucrativa, que en los últimos años tiene como presidente, con nuevas perspectivas, a Emilio Crespo. Esta Fundación conserva la colección de los Papyri Matritenses que contiene 348 papiros egipcios tanto en griego como en copto, de los siglos II a. C. hasta vII d. C. Si uno entra a su página de internet, ${ }^{26}$ puede estudiar la obra completa de Martín S. Ruipérez.

Hace años, dicho experto hospedó a distinguidos académicos extranjeros entre los cuales estuvieron Paola Vianello y Mariateresa Galaz, investigadoras del Instituto de Investigaciones Filológicas de la UNAM. Desde 1989 el estudioso creó los premios "Pastor" para las mejores tesis de licenciatura y doctorado, de latín y griego, y para trabajos destacados sobre la antigüedad clásica.

Es preciso señalar que el último libro publicado por el experto fue El mito de Edipo. Lingüística, psicoanálisis y folklore. ${ }^{27}$

\section{RUIPÉREZ Y LA CARRERA DE LETRAS CLÁSICAS}

Los cursos que el erudito impartió en la Facultad de Filosofía y Letras de la Universidad Nacional Autónoma de México fueron seguidos por una gran

\footnotetext{
${ }^{24}$ Recuérdese su traducción alemana del manual de Martin P. Nilsson, Historia de la religiosidad griega, Madrid Gredos, $1970^{2}$.

${ }^{25}$ Véase, Martín S. Ruipérez y colaboradores, Antología de La Ilíada y La Odisea, Madrid, Fundación Pastor de Estudios Clásicos, 1990.

${ }^{26}$ Véase, fundacionpastor.e.telefonica.net.

${ }^{27}$ Para más detalles, cf. Silvia Aquino López, "Ruipérez, Martín S., El mito de Edipo. Lingüística, psicoanálisis y folklore, Madrid, Alianza Editorial, 2006”, Nova Tellus, 24/2, 2006, pp. 305-311.
} 
cantidad de profesores de la Escuela Nacional Preparatoria, del Colegio de Ciencias y Humanidades, de investigadores del Centro de Estudios Clásicos, profesores de Letras Clásicas de la Facultad de Filosofía y Letras, alumnos de Posgrado e incluso algunos estudiantes preparatorianos. Los cursos que dio fueron éstos: "Sintaxis Histórica del Griego Antiguo (Verbal y Oracional)", julio de 1981; "Dialectología Griega a través de Inscripciones", julio-agosto de 1982; Cursillo de "Métrica Griega", agosto de 1982, y "Poesía Lírica Griega", julio-agosto de 1984.

Ruipérez nunca traía notas o libros bajo su brazo, salvo alguna edición de Oxford o de Teubner. Era admirable ver cómo manejaba la dialectología y la sintaxis histórica. Su enseñanza tenía siempre un sentido histórico estructural y comparativo, en latín u otras lenguas indoeuropeas. Al tomar cualquier texto él discurría de modo que todo parecía muy sencillo: fonética, fonología y sintaxis histórica, sin olvidar nunca la reiteración de leyes lingüísticas como

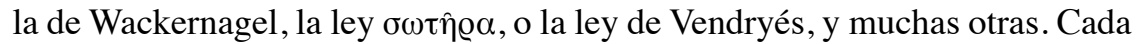
texto estaba perfectamente ubicado en su marco histórico-social, dialectal, religioso, ético, siempre con sabiduría y con buen humor, como cuando nos leía el "épodo de Colonia" de Arquíloco (PKölln inv. 7511), entonces desconocido en México, al que en Europa se denominaba "el tango de Paros", aludiendo a la famosa película del Último tango en París, de Bernardo Bertolucci (1972). ${ }^{28}$

En términos generales, estas fueron las principales aportaciones de Ruipérez en México:

En la Biblioteca Rubén Bonifaz Nuño del Instituto de Investigaciones Filológicas tenemos una parte de su obra, aunque ahora puede consultarse en la página web de la Fundación Pastor. Ruipérez ordenó toda la biblioteca del Consejo Superior de Investigaciones Científicas en su país y la de la Universidad Complutense, la había hecho también con un ordenador Hewlett-Packart HP 2 50. Elaboró programas comerciales lingüísticos, donde se permitía el corte de palabras siguiendo las reglas de la Academia de la lengua española, así como el buen uso tipográfico para textos cuando al final de una línea no se puede escribir la palabra completa e incluso versiones para diferentes lenguas modernas derivadas del latín. También desarrolló un "software" para el tratamiento científico de textos, sin olvidar los famosos textos métricos griegos codificados, además de un repertorio de inscripciones.

Tres meses después del fallecimiento de Ruipérez, el 26 de octubre de 2015, un grupo de profesores le hicimos un homenaje en la Facultad de Fi-

${ }^{28}$ Donde actuaban los jóvenes Marlon Brando y la "estupenda" (como dijo Ruipérez) María Schneider. Los españoles no podían ver esa película en su país a causa del fascismo franquista, para hacerlo tenían que atravesar los Pirineos. 
losofía y Letras, pues él había sido uno de los representantes más ilustres del mundo hispánico en el ámbito de la filología clásica y de la lingüística comparativa, y compartió con los estudiantes y profesores mexicanos algunos aspectos de su rico legado académico. El evento fue sencillo pero muy significativo, porque todos deseábamos agradecerle, de una o de otra manera, su generosa enseñanza. La Coordinadora del Colegio de Letras Clásicas de la Facultad de Filosofía y Letras, Patricia Villaseñor Cuspinera, pronunció unas palabras muy sentidas puesto que lo conoció personalmente. La autora de estas líneas hizo una semblanza académica y habló del último libro escrito por él: El mito de Edipo. Ute Schmidt presentó la ponencia "Traduciendo con Ruipérez"; Frida Zacaula participó con "Un encuentro esencial: método textual para la enseñanza del griego” y Omar Álvarez Salas expuso “¿Por qué pronunciar la ypsilon como ¿u? Francesa? 'Historia del vocalismo griego' de M. S. Ruipérez".

a) Frida Zacaula utilizó y publicó una parte del método de enseñanza de griego de Ruipérez, trabajo que él alguna vez nos mostró en clase y nos compartió. Consta de frases griegas originales que paulatinamente aumentan su dificultad lingüística. Los textos ahora pueden verse en internet: 'O öv $\theta \varrho \omega \pi o ́ s$

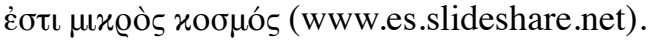

b) Paola Vianello creó un método para la enseñanza del griego, no publicado, dirigido a los profesores de la Escuela Nacional Preparatoria, se titula Lengua griega: aprendizaje, goce y cultura. ${ }^{29}$ Vianello estaba de acuerdo con las ideas de Ruipérez sobre la enseñanza de la lengua basada en el aprendizaje simultáneo de la flexión, de la sintaxis, de la formación de palabras, del vocabulario, de la fraseología, etc.

c) En el Cratilo de Platón editado por Ute Schmidt en la Bibliotheca Scriptorum Graecorum et Romanorum Mexicana en 1988 (reeditado en 2008), la traductora muestra la generosidad intelectual de Ruipérez al expresar lo siguiente: "En algunas partes del presente libro aparece como referencia 'Ruipérez'. Esto significa que el Dr. Martín S. Ruipérez - quien ha visto este trabajo- me hizo en forma oral y escrita ciertas sugerencias y aclaraciones, las cuales le agradezco muy cordialmente". ${ }^{30}$

d) Luis Alfonso Maruri Camacho (lamentablemente ya fallecido), profesor de tiempo completo de la Escuela Nacional Preparatoria quien dio cursos de Posgrado en la Facultad de Filosofía y Letras, estudió personalmente e, in-

${ }^{29}$ Cf. L. Concha Dimas, "Griego para descomponer: lengua para construir cultura", en Aquino et al., La Fascinación por la palabra. Homenaje a Paola Vianello, México, Universidad Nacional Autónoma de México (Ediciones del Centro de Estudios Clásicos), 2011, pp. $75-83$

${ }^{30}$ Cf. Platón, Cratilo, intr., versión y notas Ute Schmidt Osmanczik, México, Universidad Nacional Autónoma de México (Bibliotheca Scriptorum Graecorum et Romanorum Mexicana), 1988, p. IX. 
cluso a través de cartas, con Ruipérez, en especial, lingüística indoeuropea. Maruri estuvo una temporada con Antonio Tovar estudiando gótico e impartió ese curso en el Posgrado de la Facultad de Filosofía y Letras.

e) Omar Álvarez ha reconocido como sus maestros de lengua griega a Luis Maruri en la Escuela Nacional Preparatoria y a Ruipérez en los cursos de Posgrado de la Facultad de nuestra Universidad. Esto demuestra la impronta de Ruipérez en un preparatoriano, de manera que, en palabras de Paola Vianello, Omar Álvarez llegó a ser un "filólogo de pura cepa". ${ }^{31}$

En resumen, Ruipérez "era un sabio de las lenguas, pero era también un hombre que había conocido la vida desde la desgracia política ${ }^{32}$ sin que nunca arruinara su vida ni la de los demás: la cantidad de alumnos españoles que siguieron sus clases lo revelan. Hombre culto, conocedor de la ciencia y ávido de transmitir su conocimiento: nunca pudo dejar de ser Maestro". ${ }^{33}$ Nos adherimos a estas palabras y añadimos que en México tuvo muchos alumnos que no olvidamos su personalidad de lingüista y humanista, y su gran gusto por ser un gran Maestro del mundo griego. En México, Ruipérez nos enseñó a amar la lengua griega, a recorrerla desde sus épocas más antiguas y conocer, por lo menos, sus leyes lingüísticas fundamentales; pero lo más importante es que nos enseñó que sin Historia no hay Ciencia filológica.

$$
* * *
$$

Silvia Aquino LóPEZ es maestra en Letras Clásicas por la Universidad Nacional Autónoma de México (UNAM) e investigadora en el Centro de Estudios Clásicos del Instituto de Investigaciones Filológicas. Imparte literatura griega de la Facultad de Filosofía y Letras y es doctoranda en Letras. Ha trabajado la retórica antigua y la literatura helenística, estudiando y traduciendo a Isócrates y a Hero(n)das. Ha sido ponente en diversos congresos y coloquios nacionales e internacionales. Entre sus publicaciones recientes se encuentran Estilística griega, Jean Carrière. Adaptación y traducción del francés (UNAM, 2009) y La fascinación por la palabra. Homenaje a Paola Vianello (UNAM, 2011). Fue Secretaria de Redacción de NOVA TELLVS de 2010 a 2013. Es miembro fundador de la Asociación Mexicana de Estudios Clásicos A. C.

31 Eduard Norden, La prosa artística griega. De los orígenes a la edad Augustea, ed. Paola Vianello de Córdova, México, Universidad Nacional Autónoma de México (Manuales Universitarios, 2), 2000, p. VII.

${ }^{32} \mathrm{Cf}$. Venturas y desventuras de un niño de la guerra, Madrid, Fundación Pastor de Estudios Clásicos, 2005.

${ }^{33}$ Es un pasaje de las Memorias de León Garzón Ruipérez, catedrático emérito de Energía Nuclear de la Universidad de Oviedo y primo hermano de Martín S. Ruipérez. Cf. https:/www. lne.es/siglo-xxi/2010/01/10/7-anos-1935-di-mitin-ensenanza-colegios-religiosos/855175.html. Entrevista en La Nueva España, 03.01.2010. 